\title{
Laparoscopic Surgery for a Patient With Multiple Liver Metastases of Unknown Origin Concomitant With Gallbladder Tumor
}

\author{
YOSHIHIRO HARA ${ }^{1}$, KENSUKE YAMAMURA $^{1}$, KAZUKI MATSUMURA $^{1}$, ERI ODA $^{1}$, \\ SHINICHI AKAHOSHI ${ }^{1}$, HIDEAKI YUKI ${ }^{2}$, JUN TOMIGUCHI ${ }^{3}$, TOSHIHIKO MOTOHARA ${ }^{3}$, \\ HIDEAKI MIYAMOTO ${ }^{4}$, YOSHIHIKO KOMOHARA ${ }^{5}$ and TORU BEPPU ${ }^{1}$ \\ ${ }^{1}$ Department of Surgery, Yamaga City Medical Center, Kumamoto, Japan; \\ ${ }^{2}$ Department of Radiology, Yamaga City Medical Center, Kumamoto, Japan; \\ ${ }^{3}$ Department of Gastroenterology, Yamaga City Medical Center, Kumamoto, Japan; \\ ${ }^{4}$ Department of Medical Oncology, Yamaga City Medical Center, Kumamoto, Japan; \\ ${ }^{5}$ Department of Cell Pathology, Graduate School of Medicine, Kumamoto University, Kumamoto, Japan
}

\begin{abstract}
Background: The liver is the digestive organ where metastatic adenocarcinoma of unknown primary site is most often observed. Case Report: A 74-year-old man was diagnosed with a growing gallbladder tumor and multiple liver tumors limited to the left lateral sector. Liver tumors were suggested to be primary or secondary adenocarcinoma with no relation to the gallbladder tumor. Also for diagnostic purposes, laparoscopic full-thickness resection of the gallbladder, laparoscopic lateral sectionectomy and lymph node sampling were performed. The final histopathological diagnosis was hyperplastic polyp of the gallbladder and metastatic poorly differentiated adenocarcinoma of the liver. Liver tumors were suspected to originate from the stomach, duodenum, or small intestine; however, the primary sites could not be identified. The patient has been closely followed up without any chemotherapy 3 months after surgery. Conclusion: Laparoscopic surgery can be strongly recommended for patients with multiple liver tumors of unknown origin concomitant with a gallbladder tumor.
\end{abstract}

This article is freely accessible online.

Correspondence to: Toru Beppu, MD, Ph.D., FACS, Department of Surgery, Yamaga City Medical Center, 511, Yamaga, Kumamoto, 861-0593, Japan. Tel: +81 968442185, Fax: +81 968442420, e-mail: tbeppu@yamaga-mc.jp

Key Words: cancer of unknown primary site, liver metastases of unknown primary site, metastatic adenocarcinoma, gallbladder tumor, laparoscopic surgery.
Cancer of unknown primary site (CUP) is defined as histopathologically confirmed metastatic cancer with undiagnosed primary lesion and consists of heterogeneous features accounting for 3\%-5\% of all cancers $(1,2)$. In patients with CUP, the primary tumor can regress or stay dormant, and some malignant cells will metastasize to secondary sites early on.

Hepatocellular carcinoma (HCC), intrahepatic cholangiocarcinoma (ICC), and other tumor types occur primarily in the liver $(3,4)$. Additionally, the liver is a wellknown metastatic site of malignant tumors that spread through not only the portal but also the systemic circulation $(5,6)$. Liver metastases from gallbladder cancer are often observed adjacent to the gallbladder, especially in the perfusion area of the cystic vein, so gallbladder bed resection has been performed for potential liver metastases $(7,8)$. Liver metastases from prostate cancer are regularly observed among patients with multiple organ metastases (9).

In patients with liver metastases, to identify the primary site, various assessments are required, including patient history, serum tumor markers, detailed diagnostic imaging, as well as histopathological examination $(10,11)$. Metastatic adenocarcinoma is the most common CUP. The primary site of approximately one-third of patients of metastatic adenocarcinoma of unknown primary site (MACUP) has been identified in a digestive organ (10). Occurrence in digestive organs is significantly linked with liver [odds ratio $(\mathrm{OR})=13.21, p<0.001$ ] or lung $(\mathrm{OR}=2.36$, $p=0.001)$ metastases (10).

In the differential diagnosis of liver tumors, contrastenhanced ultrasonography (US), computed tomography (CT) and magnetic resonance imaging (MRI) are often used. Furthermore, some functional images are necessary, 

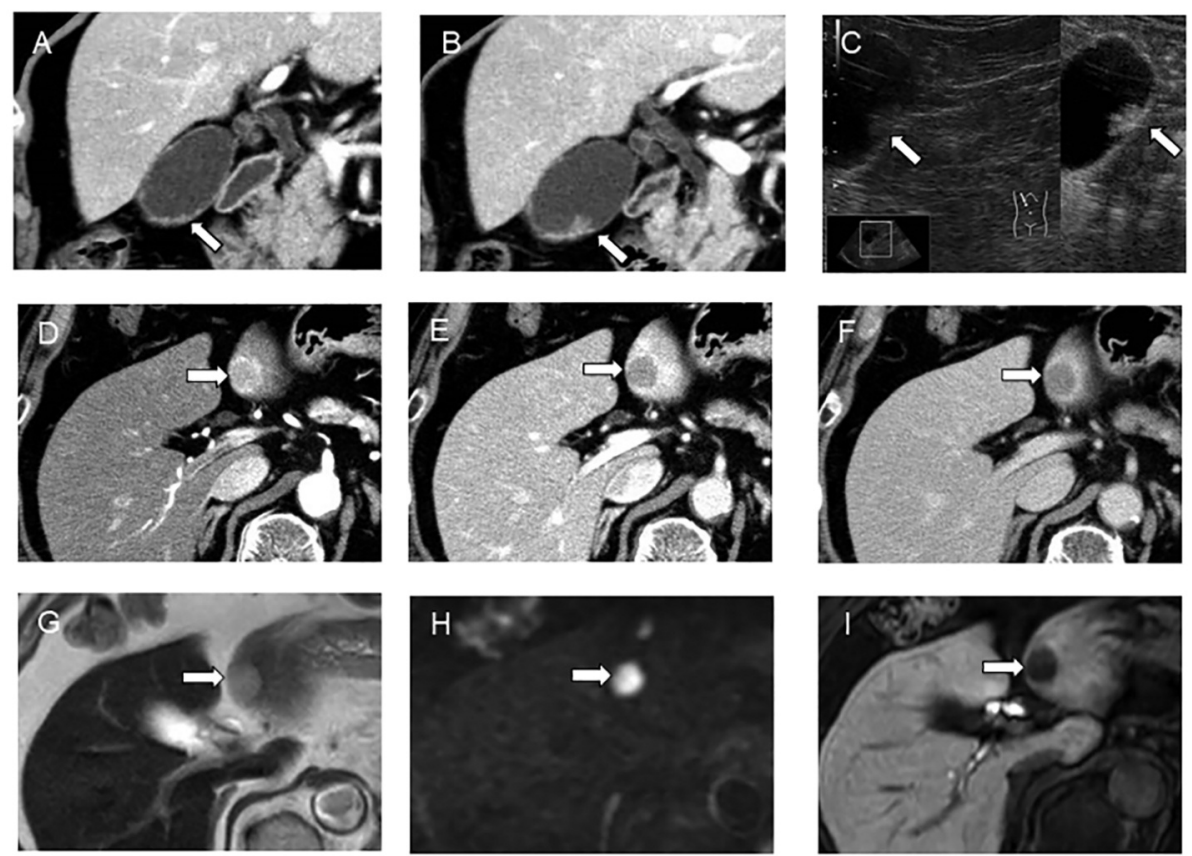

Figure 1. Preoperative diagnostic images. Contrast-enhanced computed tomography $(C T)$ coronal images in the portal venous phase showing the gallbladder tumor that tended to increase in diameter $(A, B)$. Contrast-enhanced ultrasonography shows a mulberry-type enhanced lesion in the gallbladder on the vascular phase $(C)$. Abdominal $C T$ images of the liver tumor $(D-F)$. The tumor showed an early ringed enhancement $(D)$ with prolonged peripheral enhancement $(E, F)$ during the arterial phase to equilibrium phases. Magnetic resonance $(M R)$ images $(G-I)$. T2-weighted MR image shows a mildly hyperintense tumor in the lateral segment $(G)$. Diffusion-weighted image shows hyperintensity; the mean apparent diffusion coefficient was calculated as $1.1 \times 10-3 \mathrm{~mm}^{2} / \mathrm{s}(\mathrm{H})$. Gadolinium-ethoxybenzyl-diethylenetriamine pentaacetate MR images of the hepatobiliary phase are hypointense (I). Tumor is indicated by an arrow.

including diffusion-weighted and hepato-specific MRI and nuclear metabolic imaging using positron emission tomography (PET)/CT (12). Assessment of biomarker levels including serum tumor markers is beneficial in identifying the primary origin of liver tumors $(13,14)$.

For patients with liver metastases, a large number of liver metastases is a predictor of poor prognosis after hepatectomy (15). Limited to colorectal origin, for patients with $\geq 5$ liver metastases, upfront hepatectomy is not optimal and neoadjuvant chemotherapy is recommended $(16,17)$. Liver metastases are one of the poor prognostic factors in patients with gallbladder cancer (18). However, advances in novel chemotherapy can make such patients live longer than the past (19-21).

Herein, we report a patient with liver metastases (five lesions) from CUP limited in the left lateral sector of the liver concomitant with a growing gallbladder tumor, who was successfully treated with laparoscopic surgery.

\section{Case Report}

A 74-year-old man had been undergoing follow-up for gallbladder adenomyomatosis since 2020. In the same year, he started hormone therapy for advanced prostate cancer.
Contrast-enhanced CT with a 6-month interval showed that the gallbladder lesion had a broad base and tended to increase in diameter $(10 \mathrm{~mm}$ to $18 \mathrm{~mm})$, and the entire lesion was markedly contrast-enhanced, suggesting gallbladder cancer (Figure 1A, B). The tumor was similarly well-enhanced with contrast-enhanced urtrasonography (US) (Figure 1C). At the same time, 5 hepatic mass lesions with ringed enhancement were observed limited in the lateral sector and were mostly suggested to be primary or secondly adenocarcinoma (Figure 1D-I). Liver tumors were determined as having a low possibility of metastases from gallbladder cancer based on their distribution. Carcinoembryonic antigen (CEA), carbohydrate antigen (CA19-9), and $\alpha$-fetoprotein levels were within normal range. The level of protein induced by vitamin $\mathrm{K}$ absence or antagonist-II was high $(17,021 \mathrm{mAU} / \mathrm{ml})$, possibly due to warfarin administration for atrial fibrillation. Prostate-specific antigen (PSA) was also within normal levels, so liver metastasis from prostate cancer was considered unlikely. Upper and lower gastrointestinal endoscopy showed no abnormalities. Other diagnostic images did not show lesions corresponding to the primary site of liver metastases. As a diagnostic treatment, laparoscopic surgery was performed.

On laparoscopic observation, no obvious lesions corresponding to the primary site of liver metastases were 


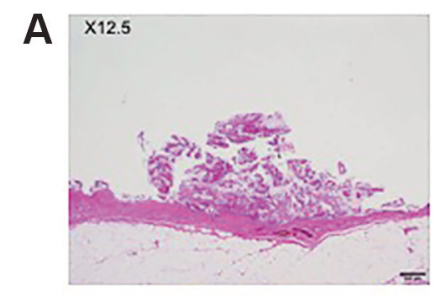

B

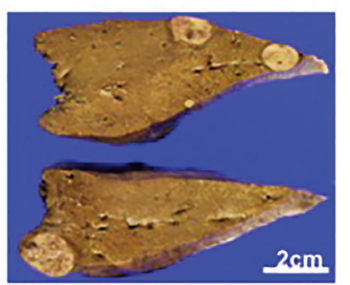

D
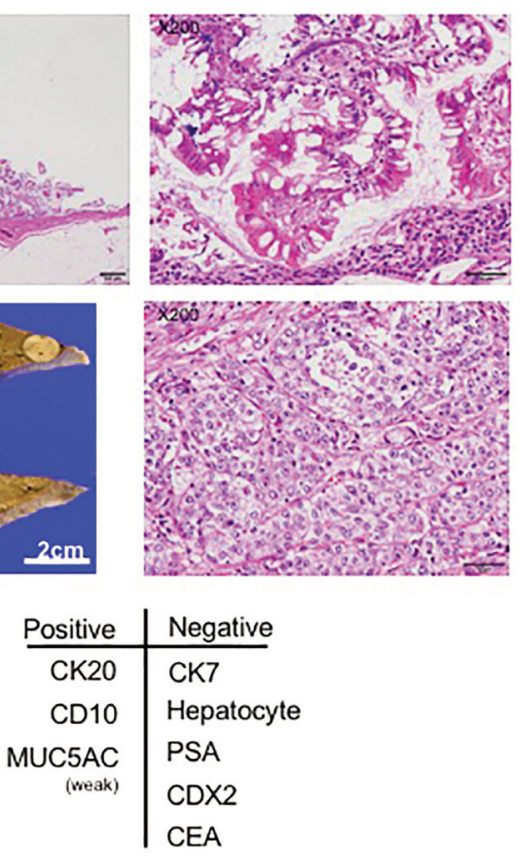

C
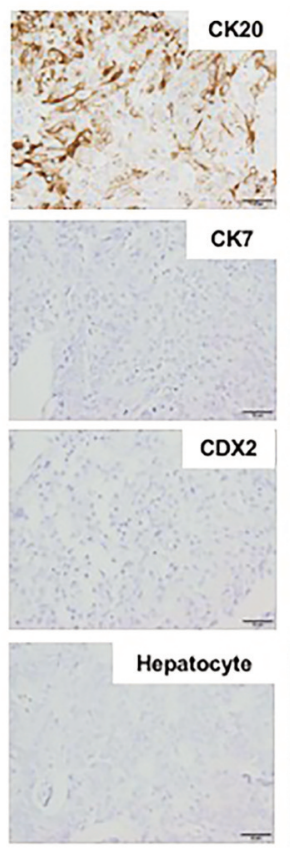

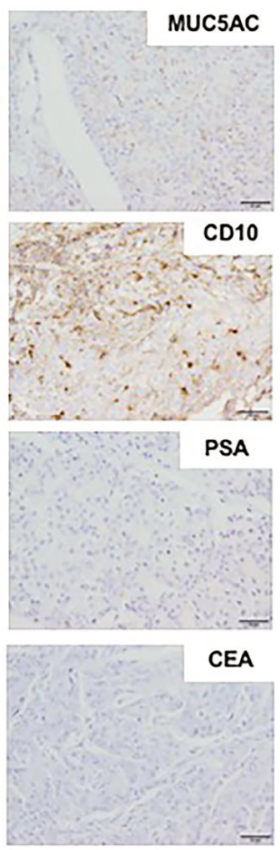

Figure 2. Histopathology-related images. (A) Hematoxylin-eosin staining shows a 5-mm polypoid lesion on the mucosal wall surface of the gallbladder. Goblet and columnar cells without atypia grew and formed papillary structures. (B) Some well-circumscribed masses were detected in the liver. (C) Liver tumors were positive for CK20, CD10 and MUC5AC and negative for CK7, hepatocytes, prostate-specific (PSA) antigen, CDK2, and carcinoembryonic antigen (CEA). (D) Summary of the immunohistochemistry.

found. Laparoscopic echo showed a well-preserved layered structure of the gallbladder wall, so early-stage gallbladder cancer or non-cancerous polyp was suspected. Laparoscopic full-thickness resection of the gallbladder (cholecystectomy inclusive of the cystic plate) and laparoscopic lateral segment resection were performed. Sampling of peri-cystic-duct and peri-bile-duct lymph node was also performed. The operative time was 343 min with a blood loss of 50 grams. Gross examination of the resected specimen showed no obvious malignant findings on the mucosal surface of the gallbladder and multiple white nodules of elastic hardness were found in the liver. With histopathological examination, polypoid lesion of the gallbladder was diagnosed as a hyperplastic polyp (Figure 2A). Some whitish and well-circumscribed masses of 2-20 mm were detected in the liver (Figure 2B). Each nodule in multiple liver lesions showed similar histological features; neoplastic cells with eosinophilic cytoplasm formed a solid nest with an irregular glandular structure. Liver lesions appeared to be poorly differentiated HCC in hematoxylin-eosin stained sections; however, HCC and ICC were excluded based on results of precise immunohistochemistry (Figure 2C). Liver tumors were positive for CK20, CD10 and MUC5AC and negative for CK7, hepatocyte, PSA, CDK2 and CEA (Figure 2D). This immune phenotype suggested the liver tumors were poorly differentiated adenocarcinoma that originated from the stomach, duodenum or small intestine $(10,22,23)$.
The postoperative course was good and the patient was discharged on the $10^{\text {th }}$ day after surgery. PET-CT was performed 1 month after surgery, but no obvious primary site was identified. Small intestine fluoroscopy showed no abnormality. We plan to examine the patient through strict follow-up without any systemic chemotherapy. The patient is currently alive with no new lesions 3 months after surgery.

\section{Discussion}

We encountered a patient with liver metastases of unknown origin concomitant with a gallbladder tumor suspected of being malignant and was synchronously treated with the laparoscopic approach. From the preoperative diagnostic images, the irregular border and ringed-enhanced liver tumors were suspected as ICC or liver metastases of adenocarcinoma; they were determined as having a low possibility of liver metastases from gallbladder cancer, based on their distribution $(24,25)$. Liver metastases from the prostate were excluded because of the stable condition of prostate cancer and normal PSA levels. No other suspicious primary lesion was detected perioperatively.

In fact, multiple liver metastases from the gallbladder and prostate are a contraindication of liver resection (7-9). A large number of liver metastases and lymph node metastases are considered poor postoperative prognostic factors of ICC, 
but ICCs with such factors were not contraindicative of liver resection $(26,27)$. Recently, some therapeutic regimens have been developed as an adjuvant therapy after liver resection $(28,29)$. Percutaneous US-guided needle biopsy of a liver tumor is one of the options to obtain histopathological diagnosis. However, needle biopsy is not recommended for highly malignant liver tumors like ICC due to the risk of intra-abdominal dissemination (30).

Histopathologically, the gallbladder tumor was diagnosed as a benign hyperplastic polyp. Based on the results of immunochemical staining, the liver tumor was diagnosed as poorly differentiated adenocarcinoma, highly suspected of liver metastases from the stomach, duodenum or small intestine $(10,22,23)$. However, postoperative whole-body PET/CT and small intestine fluoroscopy showed no suspicious primary lesion. A meta-analysis of PET/CT for patients with CUP demonstrated a primary tumor detection rate of $37 \%$ (31). At present, our patient is diagnosed with MACUP.

Laparoscopic liver resection has been widely adopted as a less invasive alternative to open liver resection $(32,33)$. For malignant liver tumors, laparoscopic liver resection can provide better short-term results and at least similar longterm prognosis (33-35). More specifically, left lateral sectionectomy is a commonly performed procedure. Laparoscopic cholecystectomy is the most common laparoscopic procedure, and laparoscopic full-thickness cholecystectomy was developed for low-grade malignant or suspicious malignant gallbladder lesions (36). For our patient, laparoscopic observation and US to detect the primary site and peritoneal dissemination, full-thickness cholecystectomy, lymph node sampling and liver resection were simultaneously performed.

Adenocarcinoma metastasis to the liver, especially of the poorly differentiated type, is classified as an unfavorable subset (2). Patients in whom liver resection is not possible are mainly treated with chemotherapy using platinum- and/or taxane-containing regimens $(11,37)$. Fortunately, our patient showed metastases limited to the liver and postoperative PET/CT demonstrated no suspicious malignant lesion; therefore, he has been followed up without any chemotherapy. If recurrence occurs, one of the aforementioned chemotherapy methods can be employed.

In conclusion, laparoscopic surgery is strongly recommended as a diagnostic treatment for liver tumors of unknown origin to achieve detailed histopathological examination. Further various laparoscopic investigations and treatments can be performed in combination.

\section{Conflicts of Interest}

All Authors have no conflicts of interest to declare in relation to this article.

\section{Authors' Contributions}

Manuscript writing: Beppu T, Hara Y, Yamamura K. Substantial contributions to conception: Matsumura K, Tomiguchi J, Motohara T, Miyamaoto H. Technical support and interpretation: Beppu T, Hara Y, Yamamura K, Yuki H, Oda E, Akahoshi S. Histopathological diagnosis: Komohara Y.

\section{References}

1 Pavlidis N and Pentheroudakis G: Cancer of unknown primary site. Lancet 379(9824): 1428-1435, 2012. PMID: 22414598. DOI: $10.1016 / \mathrm{S} 0140-6736(11) 61178-1$

2 Pavlidis N: Optimal therapeutic management of patients with distinct clinicopathological cancer of unknown primary subsets. Ann Oncol 23 Suppl 10: x282-x285, 2012. PMID: 22987978. DOI: $10.1093 /$ annonc/mds317

3 Kudo M, Kitano M, Sakurai T and Nishida N: General rules for the clinical and pathological study of primary liver cancer, nationwide follow-up survey and clinical practice guidelines: The outstanding achievements of the Liver Cancer Study Group of Japan. Dig Dis 33(6): 765-770, 2015. PMID: 26488173. DOI: $10.1159 / 000439101$

4 Massarweh $\mathrm{NN}$ and El-Serag HB: Epidemiology of hepatocellular carcinoma and intrahepatic cholangiocarcinoma. Cancer Control 24(3): 1073274817729245, 2017. PMID: 28975830. DOI: $10.1177 / 1073274817729245$

5 Weiss L, Bronk J, Pickren JW and Lane WW: Metastatic patterns and target organ arterial blood flow. Invasion Metastasis 1(2): 126-135, 1981. PMID: 7188382.

6 de Ridder J, de Wilt JH, Simmer F, Overbeek L, Lemmens V and Nagtegaal I: Incidence and origin of histologically confirmed liver metastases: an explorative case-study of 23,154 patients. Oncotarget 7(34): 55368-55376, 2016. PMID: 27421135. DOI: 10.18632 /oncotarget. 10552

7 Aloia TA, Járufe N, Javle M, Maithel SK, Roa JC, Adsay V, Coimbra FJ and Jarnagin WR: Gallbladder cancer: expert consensus statement. HPB (Oxford) 17(8): 681-690, 2015. PMID: 26172135. DOI: 10.1111/hpb.12444

8 Ertel AE, Bentrem D and Abbott DE: Gall bladder cancer. Cancer Treat Res 168: 101-120, 2016. PMID: 29206367. DOI: 10.1007/978-3-319-34244-3_6

9 Ingrosso G, Detti B, Scartoni D, Lancia A, Giacomelli I, Baki M, Carta G, Livi L and Santoni R: Current therapeutic options in metastatic castration-resistant prostate cancer. Semin Oncol 45(5-6): 303-315, 2018. PMID: 30446166. DOI: 10.1053/ j.seminoncol.2018.10.001

10 Li X, Shao Y, Sheng L, Zhu J, Wang Z, Guo K and Sun L: Risk factors and predictors for tumor site origin in metastatic adenocarcinoma of unknown primary site. Cancer Med 10(3): 974-988, 2021. PMID: 33405390. DOI: 10.1002/cam4.3684

11 Tomuleasa C, Zaharie F, Muresan MS, Pop L, Fekete Z, Dima D, Frinc I, Trifa A, Berce C, Jurj A, Berindan-Neagoe I and Zdrenghea M: How to diagnose and treat a cancer of unknown primary site. J Gastrointestin Liver Dis 26(1): 69-79, 2017. PMID: 28338116. DOI: 10.15403/jgld.2014.1121.261.haz

12 Ronot M, Clift AK, Vilgrain V and Frilling A: Functional imaging in liver tumours. J Hepatol 65(5): 1017-1030, 2016. PMID: 27395013. DOI: 10.1016/j.jhep.2016.06.024 
13 Molina R, Bosch X, Auge JM, Filella X, Escudero JM, Molina V, Solé M and López-Soto A: Utility of serum tumor markers as an aid in the differential diagnosis of patients with clinical suspicion of cancer and in patients with cancer of unknown primary site. Tumour Biol 33(2): 463-474, 2012. PMID: 22161237. DOI: $10.1007 / \mathrm{s} 13277-011-0275-1$

14 Piñero F, Dirchwolf $M$ and Pessôa MG: Biomarkers in hepatocellular carcinoma: Diagnosis, prognosis and treatment response assessment. Cells 9(6): 1370, 2020. PMID: 32492896. DOI: $10.3390 /$ cells 9061370

15 Schwarz C, Kaczirek K and Bodingbauer M: Liver resection for non-colorectal metastases. Eur Surg 50(3): 113-116, 2018. PMID: 29875799. DOI: 10.1007/s10353-018-0528-y

16 Beppu T, Sakamoto Y, Hasegawa K, Honda G, Tanaka K, Kotera Y, Nitta H, Yoshidome H, Hatano E, Ueno M, Takamura H, Baba H, Kosuge T, Kokudo N, Takahashi K, Endo I, Wakabayashi G, Miyazaki M, Uemoto S, Ohta T, Kikuchi K, Yamaue $\mathrm{H}$, Yamamoto $\mathrm{M}$ and Takada T: A nomogram predicting disease-free survival in patients with colorectal liver metastases treated with hepatic resection: multicenter data collection as a Project Study for Hepatic Surgery of the Japanese Society of Hepato-Biliary-Pancreatic Surgery. J Hepatobiliary Pancreat Sci 19(1): 72-84, 2012. PMID: 22020927. DOI: 10.1007/s00534011-0460-z

17 Beppu T, Imai K, Honda G, Sakamoto K, Kobayashi S, Endo I, Hasegawa K, Kotake K, Itabashi M, Hashiguchi Y, Kotera Y, Yamaguchi T, Tabuchi K, Kobayashi H, Yamaguchi K, Morita S, Kikuchi K, Miyazaki M, Sugihara K, Yamamoto M, Takahashi K and Joint Committee for Nationwide Survey on Colorectal Liver Metastasis: Proposal of a novel H categorybased classification of colorectal liver metastases based on a Japanese nationwide survey. J Hepatobiliary Pancreat Sci 28(4): 317-326, 2021. PMID: 33609318. DOI: 10.1002/jhbp.920

18 Yang Y, Tu Z, Ye C, Cai H, Yang S, Chen X and Tu J: Sitespecific metastases of gallbladder adenocarcinoma and their prognostic value for survival: a SEER-based study. BMC Surg 21(1): 59, 2021. PMID: 33485332. DOI: 10.1186/s12893-02101068-8

19 Shroff RT, Kennedy EB, Bachini M, Bekaii-Saab T, Crane C, Edeline J, El-Khoueiry A, Feng M, Katz MHG, Primrose J, Soares HP, Valle J and Maithel SK: Adjuvant therapy for resected biliary tract cancer: ASCO clinical practice guideline. J Clin Oncol 37(12): 1015-1027, 2019. PMID: 30856044. DOI: 10.1200/JCO.18.02178

20 Beppu T, Miyamoto Y, Sakamoto Y, Imai K, Nitta H, Hayashi H, Chikamoto A, Watanabe M, Ishiko T and Baba H: Chemotherapy and targeted therapy for patients with initially unresectable colorectal liver metastases, focusing on conversion hepatectomy and long-term survival. Ann Surg Oncol 21 Suppl 3: S405-S413, 2014. PMID: 24570379. DOI: 10.1245/s10434-014-3577-x

21 Ayez N, van der Stok EP, Grünhagen DJ, Rothbarth J, van Meerten E, Eggermont AM and Verhoef C: The use of neoadjuvant chemotherapy in patients with resectable colorectal liver metastases: Clinical risk score as possible discriminator. Eur J Surg Oncol 41(7): 859-867, 2015. PMID: 25979624. DOI: 10.1016/j.ejso.2015.04.012

22 Pavlidis N, Briasoulis E, Hainsworth $\mathrm{J}$ and Greco FA: Diagnostic and therapeutic management of cancer of an unknown primary. Eur J Cancer 39(14): 1990-2005, 2003. PMID: 12957453. DOI: 10.1016/s0959-8049(03)00547-1
23 Selves J, Long-Mira E, Mathieu MC, Rochaix P and Ilié M: Immunohistochemistry for diagnosis of metastatic carcinomas of unknown primary site. Cancers (Basel) 10(4): 108, 2018. PMID: 29621151. DOI: $10.3390 /$ cancers 10040108

24 Wang DC, Jang HJ and Kim TK: Characterization of indeterminate liver lesions on CT and MRI with contrastenhanced ultrasound: What is the evidence? AJR Am J Roentgenol 214(6): 1295-1304, 2020. PMID: 32182094. DOI: 10.2214/AJR.19.21498

25 Haj-Mirzaian A, Kadivar A, Kamel IR and Zaheer A: Updates on imaging of liver tumors. Curr Oncol Rep 22(5): 46, 2020. PMID: 32296952. DOI: 10.1007/s11912-020-00907-w

26 Uchiyama K, Yamamoto M, Yamaue H, Ariizumi S, Aoki T, Kokudo N, Ebata T, Nagino M, Ohtsuka M, Miyazaki M, Tanaka E, Kondo S, Uenishi T, Kubo S, Yoshida H, Unno M, Imura S, Shimada $M$, Ueno $M$ and Takada $T$ : Impact of nodal involvement on surgical outcomes of intrahepatic cholangiocarcinoma: a multicenter analysis by the Study Group for Hepatic Surgery of the Japanese Society of Hepato-BiliaryPancreatic Surgery. J Hepatobiliary Pancreat Sci 18(3): 443-452, 2011. PMID: 21132443. DOI: 10.1007/s00534-010-0349-2

27 Adachi T, Eguchi S, Beppu T, Ueno S, Shiraishi M, Okuda K, Yamashita Y, Kondo K, Nanashima A, Ohta M, Takami Y, Noritomi T, Kitahara K and Fujioka H: Prognostic impact of preoperative lymph node enlargement in intrahepatic cholangiocarcinoma: A multi-institutional study by the Kyushu Study Group of Liver Surgery. Ann Surg Oncol 22(7): 22692278, 2015. PMID: 25582737. DOI: 10.1245/s10434-0144239-8

28 Ben-Josef E, Guthrie KA, El-Khoueiry AB, Corless CL, Zalupski MM, Lowy AM, Thomas CR Jr, Alberts SR, Dawson LA, Micetich KC, Thomas MB, Siegel AB and Blanke CD: SWOG S0809: A phase II intergroup trial of adjuvant capecitabine and gemcitabine followed by radiotherapy and concurrent capecitabine in extrahepatic cholangiocarcinoma and gallbladder carcinoma. J Clin Oncol 33(24): 2617-2622, 2015. PMID: 25964250. DOI: 10.1200/JCO.2014.60.2219

29 Yoo C, Shin SH, Park JO, Kim KP, Jeong JH, Ryoo BY, Lee W, Song KB, Hwang DW, Park JH and Lee JH: Current status and future perspectives of perioperative therapy for resectable biliary tract cancer: a multidisciplinary review. Cancers (Basel) 13(7): 1647, 2021. PMID: 33916008. DOI: 10.3390/cancers 13071647

30 Yamamura K, Beppu T, Oda E, Sato N, Yuki H, Motohara T, Miyamoto H, Miyamura S, Onishi K, Komohara Y and Akahoshi $\mathrm{S}$ : Hepatic inflammatory pseudotumor mimicking malignant tumor with rare onset of intra-abdominal hemorrhage. Anticancer Res 41(5): 2727-2732, 2021. PMID: 33952504. DOI: 10.21873/anticanres.15054

31 Kwee TC and Kwee RM: Combined FDG-PET/CT for the detection of unknown primary tumors: systematic review and meta-analysis. Eur Radiol 19(3): 731-744, 2009. PMID: 18925401. DOI: $10.1007 / \mathrm{s} 00330-008-1194-4$

32 Abu Hilal M, Aldrighetti L, Dagher I, Edwin B, Troisi RI, Alikhanov R, Aroori S, Belli G, Besselink M, Briceno J, Gayet B, D'Hondt M, Lesurtel M, Menon K, Lodge P, Rotellar F, Santoyo J, Scatton O, Soubrane O, Sutcliffe R, Van Dam R, White S, Halls MC, Cipriani F, Van der Poel M, Ciria R, Barkhatov L, GomezLuque Y, Ocana-Garcia S, Cook A, Buell J, Clavien PA, Dervenis C, Fusai G, Geller D, Lang H, Primrose J, Taylor M, Van Gulik T, Wakabayashi G, Asbun H and Cherqui D: The Southampton 
Consensus guidelines for laparoscopic liver surgery: From indication to implementation. Ann Surg 268(1): 11-18, 2018. PMID: 29064908. DOI: 10.1097/SLA.0000000000002524

33 Yamamoto M, Yoshida M, Furuse J, Sano K, Ohtsuka M, Yamashita S, Beppu T, Iwashita Y, Wada K, Nakajima TE, Sakamoto K, Hayano K, Mori Y, Asai K, Matsuyama R, Hirashita T, Hibi T, Sakai N, Tabata T, Kawakami H, Takeda H, Mizukami T, Ozaka M, Ueno M, Naito Y, Okano N, Ueno T, Hijioka S, Shikata S, Ukai T, Strasberg S, Sarr MG, Jagannath P, Hwang TL, Han HS, Yoon YS, Wang HJ, Luo SC, Adam R, Gimenez M, Scatton O, Oh DY and Takada T: Clinical practice guidelines for the management of liver metastases from extrahepatic primary cancers 2021. J Hepatobiliary Pancreat Sci 28(1): 1-25, 2021. PMID: 33200538. DOI: $10.1002 /$ jhbp. 868

34 Beppu T, Wakabayashi G, Hasegawa K, Gotohda N, Mizuguchi T, Takahashi Y, Hirokawa F, Taniai N, Watanabe M, Katou M, Nagano H, Honda G, Baba H, Kokudo N, Konishi M, Hirata K, Yamamoto M, Uchiyama K, Uchida E, Kusachi S, Kubota K, Mori M, Takahashi K, Kikuchi K, Miyata H, Takahara T, Nakamura M, Kaneko H, Yamaue H, Miyazaki M and Takada T: Long-term and perioperative outcomes of laparoscopic versus open liver resection for colorectal liver metastases with propensity score matching: a multi-institutional Japanese study. J Hepatobiliary Pancreat Sci 22(10): 711-720, 2015. PMID: 25902703. DOI: $10.1002 /$ jhbp. 261
35 Takahara T, Wakabayashi G, Beppu T, Aihara A, Hasegawa K, Gotohda N, Hatano E, Tanahashi Y, Mizuguchi T, Kamiyama T, Ikeda T, Tanaka S, Taniai N, Baba H, Tanabe M, Kokudo N, Konishi M, Uemoto S, Sugioka A, Hirata K, Taketomi A, Maehara Y, Kubo S, Uchida E, Miyata H, Nakamura M, Kaneko H, Yamaue H, Miyazaki $M$ and Takada $T$ : Long-term and perioperative outcomes of laparoscopic versus open liver resection for hepatocellular carcinoma with propensity score matching: a multi-institutional Japanese study. J Hepatobiliary Pancreat Sci 22(10): 721-727, 2015. PMID: 26096910. DOI: 10.1002/jhbp.276

36 Han HS, Yoon YS, Agarwal AK, Belli G, Itano O, Gumbs AA, Yoon DS, Kang CM, Lee SE, Wakai $\mathrm{T}$ and Troisi RI: Laparoscopic surgery for gallbladder cancer: An expert consensus statement. Dig Surg 36(1): 1-6, 2019. PMID: 29339660. DOI: $10.1159 / 000486207$

37 Lazaridis G, Pentheroudakis G, Fountzilas G and Pavlidis N: Liver metastases from cancer of unknown primary (CUPL): a retrospective analysis of presentation, management and prognosis in 49 patients and systematic review of the literature. Cancer Treat Rev 34(8): 693-700, 2008. PMID: 18584969. DOI: $10.1016 /$ j.ctrv.2008.05.005

Received May 19, 2021

Revised June 9, 2021

Accepted June 11, 2021 